\title{
Characterization of Pore Structure of Microbial Foam Concrete and Its Influence on Properties
}

\author{
Jie Cao ${ }^{1}$, Rui Xu ${ }^{2, *}$, Nan Zhang ${ }^{1}$, Lei Zhang ${ }^{2,3}$ and Xiaohang $\mathrm{Ji}^{4}$ \\ ${ }^{1}$ Hebei Petroleum University of Technology, Chengde 067000, China \\ ${ }^{2}$ School of Materials Science and Engineering, Tianjin Chengjian University, Tianjin 300384, China \\ ${ }^{3}$ Tianjin Key Laboratory of Building Green Functional Materials, Tianjin Chengjian University, Tianjin 300384, China \\ ${ }^{4}$ Pennsylvania State University, Pennsylvania 16802-1408, United States
}

Received 11 December 2020; Accepted 2 May 2021

\begin{abstract}
Foam concrete, a novel inorganic wall insulation material, has been widely studied and used to as an improvement of traditional inorganic wall insulation materials. Microbial foam concrete is composed of basic materials in the solid phase and pores in the gas phase. A non-destructive three-dimensional (3D) pore structure model was established in this study to investigate the performance of microbial foam concrete and reveal the influence of pore structure, porosity, pore size distribution, and pore shape factor on compressive strength, thermal conductivity, and water absorption. The pore images were collected using an ultra-depth-of-field microscope at the surface of the microbial foam concrete, and the image analysis software ImageJ processed the pore structure, in order to characterize the average pore size, porosity, pore shape factor, and pore size distribution of microbial foam concrete with a density grade of 300-1200. Results show that with the increase of the density grade of the microbial foam concrete, compressive strength and thermal conductivity gradually increase whereas water absorption, porosity, and average pore diameter decrease. The pore shape factor increases and approaches 1 . The microbial foam concrete samples with a density grade of 700 are scanned and tested using computed tomography, and 3D reconstruction of the 2D CT images is carried out by using visualization software Avizo. The pore structure is quantitatively analyzed, and the non-destructive $3 \mathrm{D}$ pore structure model is obtained, which is consistent with the analysis results of the influence of pore structure on its performance. The study provides a reference for the application of microbial foam concrete.
\end{abstract}

Keywords: Microbial foam concrete, Image analysis, X-ray computed tomography (X-CT), Pore structure

\section{Introduction}

As a kind of lightweight concrete, microbial foam concrete is prepared by adding foaming agent to introduce pores into cement paste [1-3]. With the advantages of lightweight, high strength, good heat preservation, sound insulation and integrity, simple construction, and low cost, microbial foam concrete can be used in various fields, such as subgrade, bridge, and culvert backfill, ground insulation, and heat insulation wallboard [4]. In recent years, microbial foam agent has been widely concerned by scholars because of its good stability. Moreover, high-efficiency protein foam agents have been developed in the United States, Italy, and Japan.

Microbial foam concrete is composed of basic materials in the solid phase and pores in the gas phase. Its compressive strength and thermal conductivity are related to the distribution and structure of pores. The current test methods of pore structure focus on the microscopic level, such as adsorption method and mercury intrusion porosimetry (MIP). However, the size, distribution, and shape of the pores in microbial foam concrete at the macroscopic level are also important factors.

X-ray computed tomography (X-CT) technology has

*E-mail address: yingyonghuaxue32@163.com

ISSN: 1791-2377 @ 2021 School of Science, IHU. All rights reserved.

doi:10.25103/jestr.143.18 been used to analyze aggregate, mortar, and cracks, as well as in the study of the internal structure of concrete $[5,6]$. After threshold segmentation of image slices captured by XCT technology, the three-dimensional (3D) models of pores with different sizes are reconstructed based on 3D image modeling technology [7]. However, the influence of pore structure on the compressive strength, thermal conductivity, and water absorption of microbial-foamed concrete is still unclear. Therefore, it is an urgent problem to prepare foamed concrete with microorganism composite foaming agent with good comprehensive performance and determine the influence of pore structure, porosity, pore size distribution, and pore shape on its compressive strength and thermal conductivity.

In this study, an ultra-depth-of-field microscope is applied to collect the pore images of microbial foam concrete surface and characterize the pore structure by using image analysis software ImageJ. Moreover, the influence of pore structure on the compressive strength, thermal conductivity, and water absorption of microbial foam concrete is studied. A microbial foam concrete sample with a density grade of 700 is scanned and tested by using X-CT. Based on visualization software Avizo, 3D reconstruction is realized for the $2 \mathrm{D} \mathrm{CT}$ images, the pore structure is quantitatively analyzed, and a non-destructive $3 \mathrm{D}$ pore structure model is obtained. 


\section{State of the art}

As a novel lightweight insulation material, foam concrete has the special functions of heat preservation, sound insulation, and fire prevention, and has been widely used in constructional engineering (insulation wall) [7]. Its performance is directly influenced by the pore structure of foam concrete. Therefore, scholars have carried out numerous studies of the pore structure of foam concrete.

The analysis methods for pore structure of foam concrete include MIP, low-temperature nitrogen adsorptiondesorption method (BET), X-ray diffraction (XRD), and ultrasonic pulse velocity (UPV). Based on pore throat size, Dong [8] estimated the permeability of artificial sandstone with different particle sizes and evaluated the influence of sample size on the permeability of artificial sandstone. However, in contact measurement, MIP inevitably destroyed the pore structure of foam concrete, resulting in the error of the measurement results. Zhou Qing [9] pointed out that the sample size measured by MIP was limited, and the aperture range was generally less than $360 \mu \mathrm{m}$. Therefore, it was not suitable for foam concrete testing. According to Yun T. [10], BET was mainly used to analyze the nanoporous structure of foam concrete, whereas microbial foam concrete contained a large number of macro pores. Alengaram [11] carried out Xray diffraction (XRD) analysis to evaluate the pore structure of lightweight foam concrete. However, macro stress leaded to the errors of pore analysis. As argued by Miramini [12], UPV was mainly applied to field inspection of ordinary concrete, but it was rarely used for the inspection of foam concrete due to its particularity. Yoshitake [13-15] pointed out that computer image processing technology had become a new method for analyzing the pore structure of porous materials. In the field of image processing, HP Tang [16] used 2D image processing to analyze the pore structure of materials. Lan et al., Jiang et al. [17,18] impregnated foam cement samples with vacuum resin, hardened and polished, and then took photos of the samples with stereomicroscope. By using Image Pro Plus, the parameters such as porosity, pore area, and pore wall thickness were obtained. Zhou [19] used a digital microscope to take pictures of hardened foam concrete samples, observe, and analyze its internal pore structure through image processing software Image $\mathrm{J}$, and calculated parameters such as porosity, average equivalent diameter, and spatial average pore diameter. This method had promoted the study of foam concrete microstructure, but it had several defects. The traditional image detection method based on 2D measurement cannot achieve the expected experimental results because the image quality is influenced by uncertain factors such as ambient light and camera.

Targeting on the problems during the inspection of foam concrete pore structure, 1. Gomes [20,21] used a pore structure analysis method based on 3D measurement, namely, X-CT. In 3D measurement, structured light 3D reconstruction technology can scan object surface continuously and quickly, and reconstruct the corresponding 3D data. By combining X-CT technology and Watershed Split technology, Pang Chaoming [22] measured the pore size and shape factor of foam concrete, obtained the pore size distribution and shape factor distribution, and realized non-destructive quantitative characterization of the pore structure of foam concrete. Taesun [23] used 3D image modeling technology to reconstruct real $3 \mathrm{D}$ models of the pores with different sizes. The $3 \mathrm{D}$ structure of foam concrete was used to extract holes, thus improving the accuracy of hole edge segmentation.

The above studies focused on the pore structure of foam concrete, but few studies analyzed the influence of pore structure on the performance of foam concrete, especially the characterization and quantitative analysis of pore structure. Therefore, the images of pores on the surface of microbial foam concrete are collected by using an ultradepth-of-field microscope, and the pore structure is characterized by using image analysis software Image J in this study. Moreover, the influence of pore structure on the compressive strength, thermal conductivity, and water absorption of microbial foam concrete is studied. The samples of microbial foam concrete with a density grade of 700 are scanned and tested by X-CT, and 3D reconstruction is implemented for the 2D CT images by using visualization software Avizo. The pore structure is quantitatively analyzed, and a non-destructive $3 \mathrm{D}$ pore structure model is obtained.

The remainder of this study is organized as follows. The raw materials, test device, test methods, and preparation of foam concrete are described, and the test methods for the pore structure performance of foam concrete are analyzed in Section 3. The images of pores on the surface of microbial foam concrete are collected by using an ultra-depth-of-field microscope. The pore structure is characterized by image analysis software ImageJ, the effects of pore structure on compressive strength, thermal conductivity, and water absorption of microbial foam concrete are studied, and the physical and mechanical properties of foam concrete with different densities are obtained in Section 4. Finally, the summary and relevant conclusions are drawn in Section 5.

\section{Methodology}

\subsection{Raw materials}

Cement: 42.5-grade ordinary Portland cement of Tianjin Jidong Cement Co., Ltd. Foaming agent: microbial foaming agent prepared in the laboratory, with foaming ratio of 15 times, $1 \mathrm{~h}$ bleeding rate of $48 \%$, and $1 \mathrm{~h}$ settling distance of 2 $\mathrm{mm}$. Water reducing agent: Subot PCA-1 polycarboxylic acid high-performance water reducing agent with water reducing rate of $25 \%$. Physical properties of ordinary Portland cement are shown in Table 1.

Table 1. Physical properties of ordinary Portland cement

\begin{tabular}{|c|c|c|c|c|c|c|}
\hline \multicolumn{2}{|c|}{$\begin{array}{l}\text { Coagulation } \\
\text { time/min }\end{array}$} & \multirow{2}{*}{ Stability } & \multicolumn{2}{|c|}{$\begin{array}{l}\begin{array}{l}\text { Compressive } \\
\text { strength/MPa }\end{array} \\
\end{array}$} & \multicolumn{2}{|c|}{$\begin{array}{l}\text { Flexural } \\
\text { strength/MPa }\end{array}$} \\
\hline $\begin{array}{l}\text { Initial } \\
\text { set }\end{array}$ & $\begin{array}{l}\text { Final } \\
\text { set }\end{array}$ & & 3d & 28d & 3d & 28d \\
\hline 196 & 247 & Qualified & 31.6 & 53.2 & 6.3 & 8.7 \\
\hline
\end{tabular}

\subsection{Test equipment and instruments}

As a porous lightweight building material, foam concrete is used as its main performance index, such as dry density, compressive strength and thermal conductivity. All the indexes are operated according to the relevant specifications. The test equipment and instruments are shown in Table 2.

Table 2. Test equipment and instruments

\begin{tabular}{l|l|l}
\hline Equipment name & Manufacturer & Model \\
\hline $\begin{array}{l}\text { Foam concrete } \\
\text { mixer }\end{array}$ & Beijing Yashe Building & \\
& Materials Building Materials & YS-TS-40 \\
Air dry oven & Technology Co., Ltd & \\
Compressive & Shanghai Yiheng Scientific & DHG- \\
& Instrument Co., Ltd & $9030 \mathrm{~A}$ \\
& Shandong Jianli Detection & YAW-2000
\end{tabular}




\begin{tabular}{l|l|l}
$\begin{array}{l}\text { strength tester } \\
\text { Thermal } \\
\text { conductivity } \\
\text { analyzer }\end{array}$ & Technology Co., Ltd & \\
$\begin{array}{l}\text { Ultra-depth-of- } \\
\text { field electron } \\
\text { microscope }\end{array}$ & Manufacturing Co., Ltd & HFM 463/3 \\
\hline
\end{tabular}

\subsection{Raw Experiment method}

\subsubsection{Preparation of microbial foam concrete}

Cement, polycarboxylate water reducing agent, and water were uniformly stirred according to the mixture ratio (watersolid ratio was 0.35 , and water reducing agent accounted for $0.5 \%$ of cement). The microbial foaming agent was stirred into uniform foam at high speed, was poured into cement paste, and stirred uniformly for 2-3 min. The two materials were uniformly mixed and were poured into a cube mold with a side length of $100 \mathrm{~mm}$ for molding. After curing at room temperature for $24 \mathrm{~h}$, the test block was demolded, and cured in a curing box with constant temperature and humidity (temperature $(20 \pm 2)^{\circ} \mathrm{C}$, relative humidity above $95 \%$ ) to the specified age.

\subsubsection{Proportion of biobased foam concrete with different density grades}

According to Formula (1), the proportion of biobased foam concrete with different density grades was calculated as follows:

$$
\left.\begin{array}{l}
\rho=S_{a} M_{c} \\
M_{w}=\phi M_{c} \\
V_{1}=\frac{M_{c}}{\rho_{C}}+\frac{M_{w}}{\rho_{W}} \\
V_{2}=K\left(1-V_{1}\right)
\end{array}\right\}
$$

Where $\rho$ is the designed dry density of foam concrete, $\mathrm{kg} / \mathrm{m}^{3} . S_{a}$ is the mass coefficient, which is 1.2 for ordinary Portland cement and 1.4 for sulphoaluminate cement. $M_{c}$ is the cement content of foam concrete, $\mathrm{kg} . M_{w}$ is the basic water consumption of foam concrete, $\mathrm{kg} . \varphi$ is the basic water cement ratio. $\rho_{c}$ is the cement density, which is $3100 \mathrm{~kg} / \mathrm{m}^{3} . \rho_{w}$ is the density of water, which is $1000 \mathrm{~kg} / \mathrm{m}^{3} . V_{1}$ is the total volume of the slurry composed of cement and water before adding foam, $\mathrm{m}^{3} . V_{2}$ is the foam addition amount, $\mathrm{m}^{3} . \mathrm{K}$ is the surplus coefficient, which is usually greater than 1 . It depends on foam quality and foaming time, and is usually $1.1-1.3$. In this study, $\mathrm{K}$ is 1.2 .

\subsubsection{Test method for pore structure performance of microbial foam concrete}

(1) Porosity test: The test block cured to the age was cut with a cutting machine, polished with 400-mesh and 800mesh sandpaper, and vibrated in an ultrasonic wave. After the powder was removed, it was dried in a drying oven. The broken face pore structure was then photographed under an ultra-depth-of-field microscope and an scanning electron microscope (Fig.1 and Fig.2), and the photos were imported into the software for analysis, Porosity, pore size distribution, average pore size, and pore shape factor were obtained based on various test parameters in software ImageJ. The cross section of microbial foam concrete after binarization treatment is shown in Fig. 3 and Fig. 4.

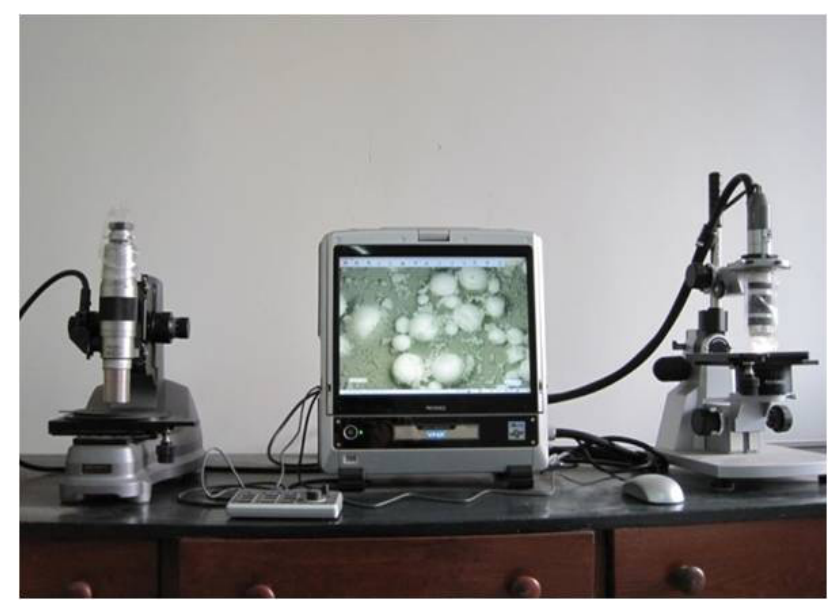

Fig. 1. Super-depth-of-field microscope

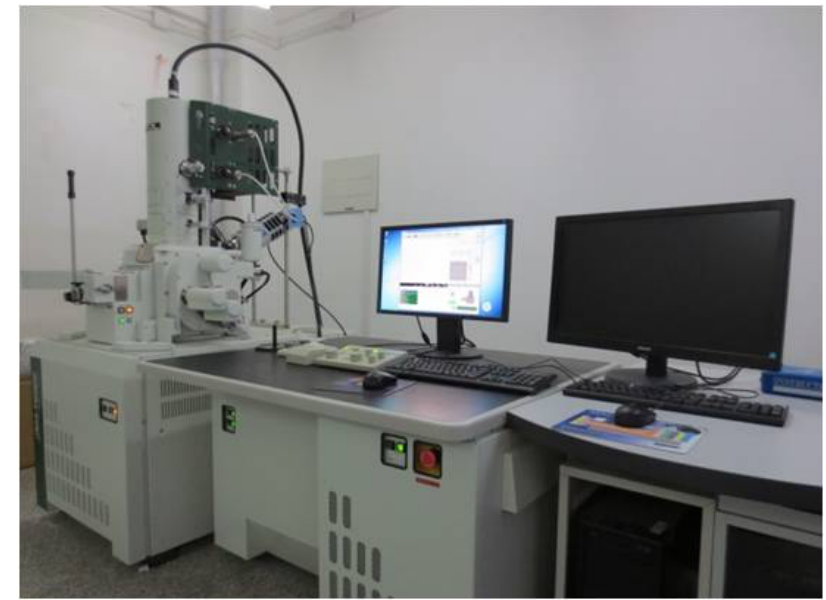

Fig. 2. Scanning electron microscope

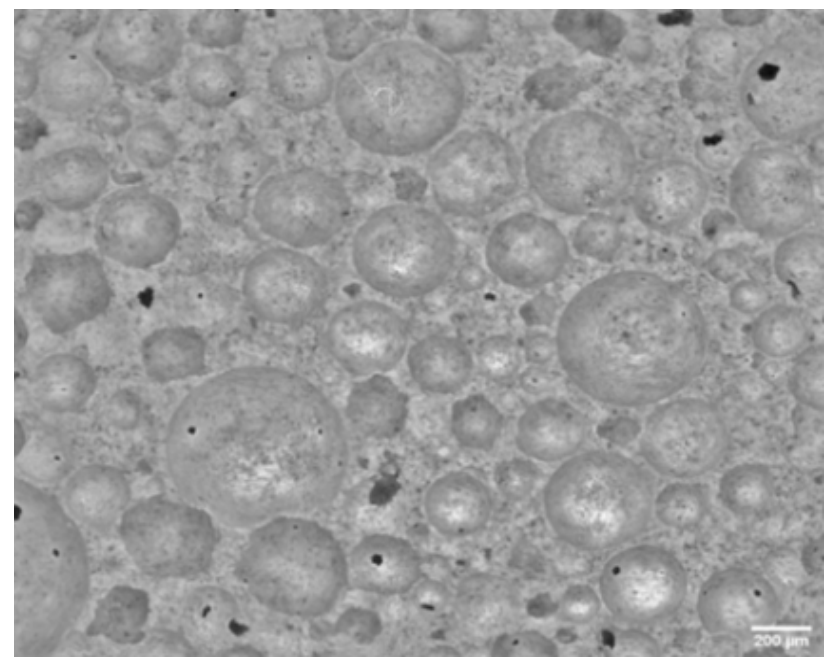

Fig. 3. Microbial foam concrete section

(2) X-CT, manufactured by Tianjin Sanying Precise Instruments Co., Ltd., was nanoVoxel-3000 with current of $60 \mu \mathrm{A}$, test voltage of $110 \mathrm{kV}$, and resolution of $18.5 \mu \mathrm{m}$. A 3D model of the processed CT images was established, and the general process is shown in Fig. 5 [24]. 


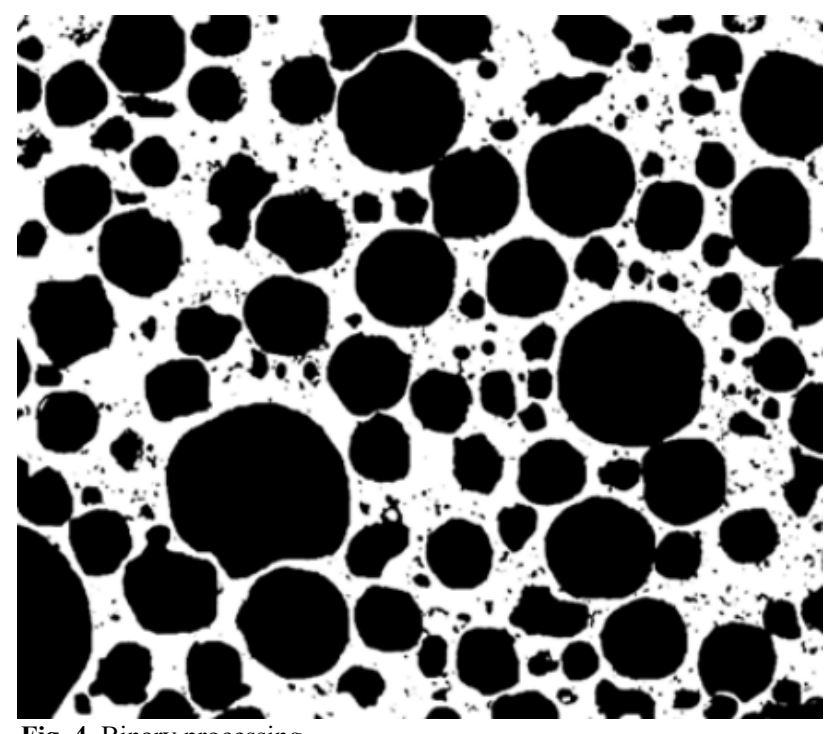

Fig. 4. Binary processing
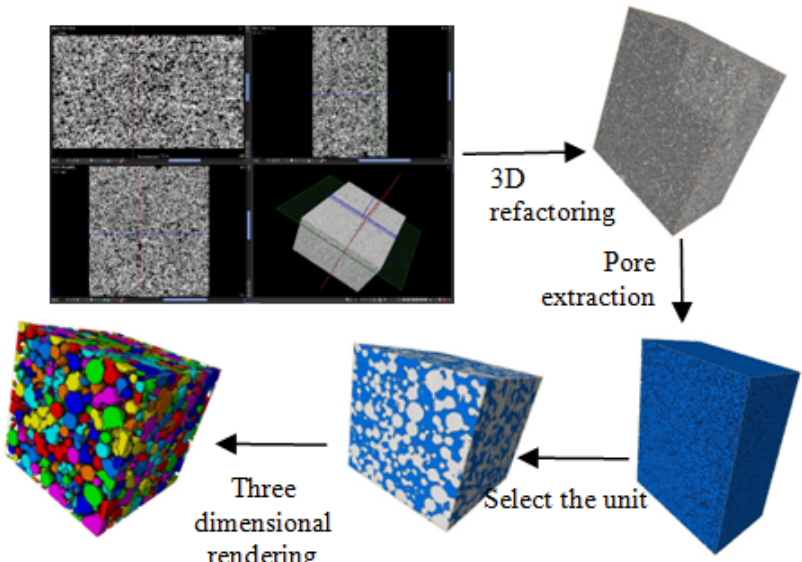

\section{Result analysis and discussion}

4.1 Compressive strength, thermal conductivity, and water absorption of microbial foam concrete

The water-solid ratio of microbial foam concrete was 0.35 , and the content of water reducing agent accounted for $0.5 \%$ of cement. The actual density from S03 to $\mathrm{S} 11$ is shown in Figs. 6(e). The compressive strength, thermal conductivity, and water absorption of microbial foam concrete under different density grades are shown in Table 3. According to the analysis results, with the increase of the density grade, compressive strength and thermal conductivity gradually increase while water absorption decreases. as shown in Figs. 6(a), 6(b) and 6(c). Foam parameters have a remarkable influence on density grade, and the parameters and density change linearly. However, the increase of concrete density leads to the decrease of water absorption, especially water absorption of S03 to S04 decreases substantially. With the increase of concrete density, water absorption decreases slowly and becomes balanced. As density increases, compressive strength and thermal conductivity gradually increase. After density reaches S10, compressive strength increases slightly, and the density has a minimal influence. With the increase of density grade, the foam parameter decreases, as shown in Figs. 6(d), the foam is distributed evenly in the slurry, and the amount of cement paste increases. Therefore, the pore size of microbial foam concrete is smaller, and the distribution is uniform.

Fig. 5. General process of building 3D model

Table. 3. Performance analysis of A03-A12 microbial foam concrete

\begin{tabular}{|c|c|c|c|c|c|}
\hline $\begin{array}{l}\text { Density grade } \\
\left(\mathrm{kg} / \mathrm{m}^{3}\right)\end{array}$ & $\begin{array}{l}\text { Proportion of foam } \\
\text { to solid material } \\
(\%)\end{array}$ & $\begin{array}{l}\text { Actual density } \\
\left(\mathrm{kg} / \mathrm{m}^{3}\right)\end{array}$ & $\begin{array}{l}\text { Water absorption } \\
(\%)\end{array}$ & $\begin{array}{l}\text { Thermal conductivity } \\
(\mathbf{W} /(\mathbf{m} \cdot \mathbf{K}))\end{array}$ & $\begin{array}{l}\text { Compressive strength } \\
\text { (MPa) }\end{array}$ \\
\hline S03 & 26.4 & 346 & 67.7 & 0.08 & 0.8 \\
\hline S04 & 19.1 & 444 & 26.4 & 0.10 & 1.2 \\
\hline S05 & 17.8 & 502 & 20.9 & 0.12 & 1.5 \\
\hline S06 & 13.5 & 598 & 13.4 & 0.14 & 2.6 \\
\hline S07 & 11.6 & 684 & 11.8 & 0.17 & 3.7 \\
\hline S08 & 11.0 & 796 & 10.4 & 0.19 & 4.6 \\
\hline S09 & 9.5 & 926 & 8.9 & 0.21 & 6.3 \\
\hline $\mathrm{S} 10$ & 8.1 & 965 & 8.8 & 0.23 & 9.5 \\
\hline S11 & 6.1 & 1167 & 6.5 & 0.27 & 10.3 \\
\hline
\end{tabular}

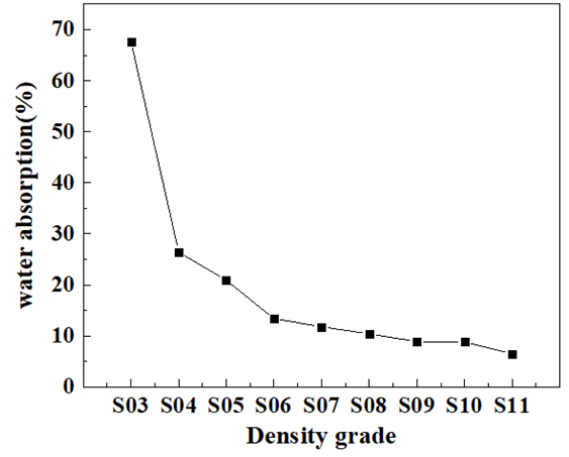

(a) Water absorption

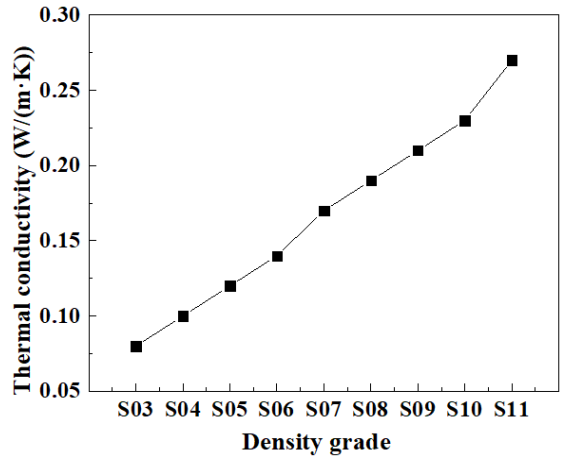

(b) Thermal conductivity 


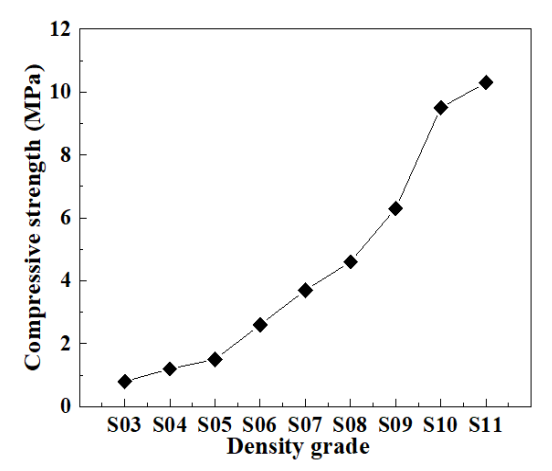

(c) Compressive strength

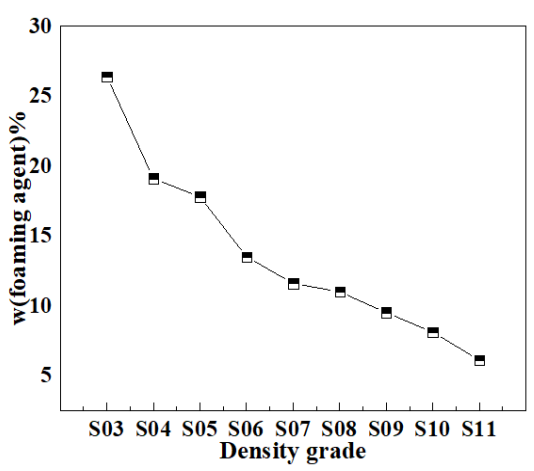

(d) Foaming agent

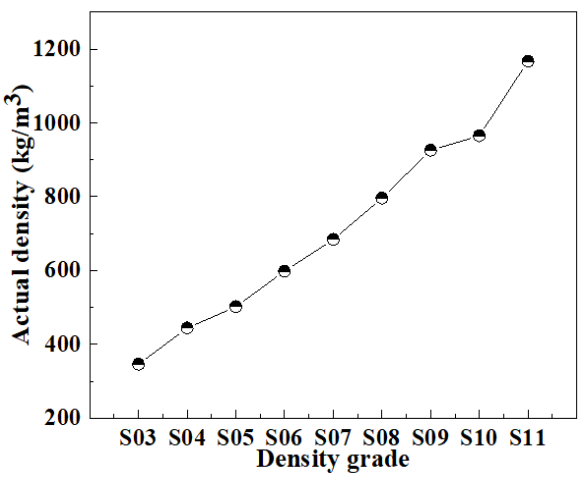

(e) Actual density

Fig. 6. Performance analysis of A03-A12 microbial foam concrete.

\subsection{Characterization of pore structure of microbial foam concrete}

4.2.1 Porosity, average pore size, and pore shape factor of microbial foam concrete with different density grades

The pore structure of the microbial foam concrete with different density grades is shown in Fig. 7. While the density grade increase, the porosity and average pore diameter of the microbial foam concrete gradually decrease, whereas the pore shape factor generally increases. This behavior is consistent with the results found by Pang et al. [22], Zhang et al. [25], and Hilal et al. [26], that is, the average equivalent pore size and shape factor of foam concrete gradually increase with the decrease of density grade. When the density grade of the microbial foam concrete is 1200 , the porosity is $45.8 \%$, the average pore diameter is $127.9 \mu \mathrm{m}$, and the pore shape factor is 0.910 . When the density grade increases from 300 to 800 , the porosity decreases from $74.6 \%$ to $51.3 \%$, the average pore size decreases from 420.5 $\mu \mathrm{m}$ to $151.0 \mu \mathrm{m}$, and the pore shape factor increases to 0.895 . The main reason is that when the density grade of microbial foam concrete increases, the needed dosage of microbial foam decreases, resulting in a decrease in the amount of gas [27]. The bubbles in the slurry are evenly distributed, and the position where the bubbles replace the slurry after condensation and hardening becomes smaller. Therefore, the porosity of the microbial foam concrete decreases, and the pore wall thickness and the compressive strength increase clearly. The proportion of gas-phase heat conduction decreases gradually, the thermal conductivity increases continuously, and the number of intercommunicating pores decreases. The water absorption rate of macroscopic pores is reduced and the pore diameter of microbial foam concrete decreases. The pore structure is closer to the sphere, the bubble wall is smoother, the pore shape factor is larger, and the internal stress of microbial foam concrete is smaller [28].

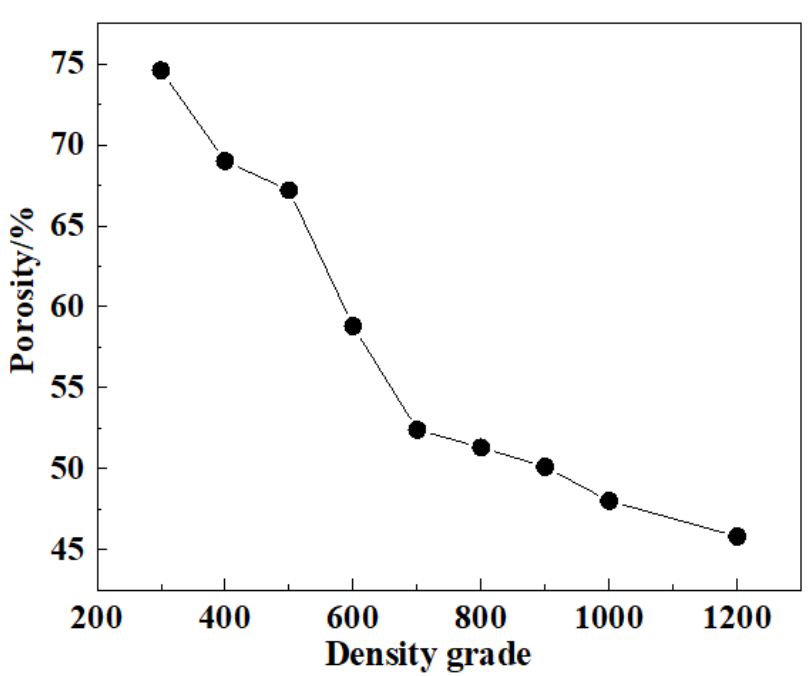

(a) Porosity

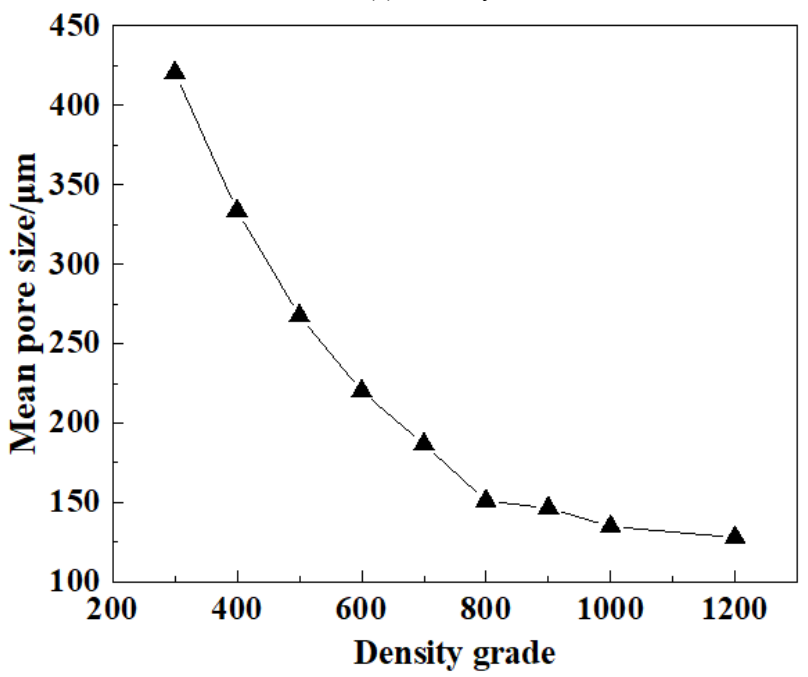

(b) Mean pore size 


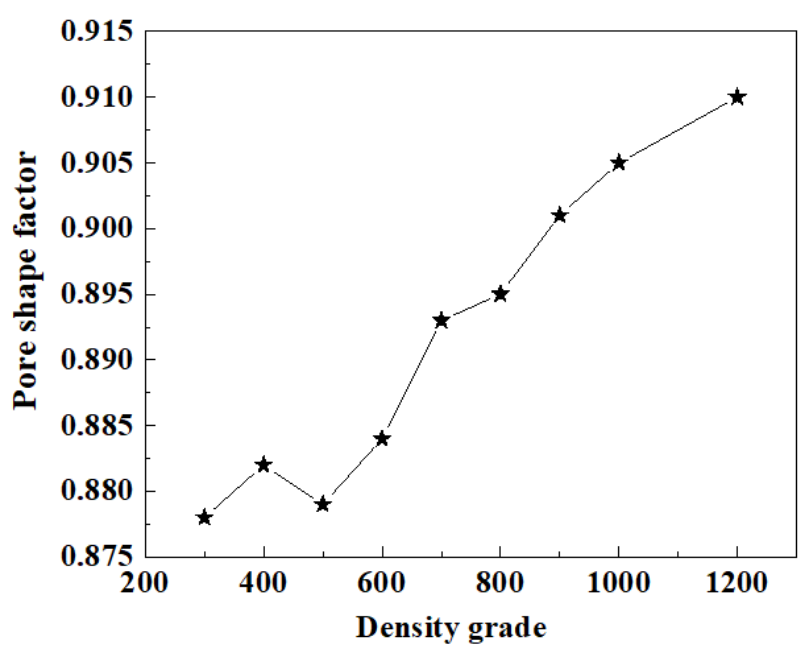

(c) Pore shape factor

Fig. 7. Hole structure of microbial foam concrete with different density grades.

\subsubsection{Pore size distribution of microbial foam concrete with different density grades}

Fig.8 shows the cumulative pore size distribution of microbial foam concrete with different density grades. The pore size distribution of microbial foam concrete with high density is more uniform than that with low density, mainly because with the increase of the density grade, the foam content in solid material decreases, and most pores are closed pores with relatively small pore size, which are evenly distributed in the slurry. The compressive strength and water absorption are improved, and the thermal conductivity is weakened.

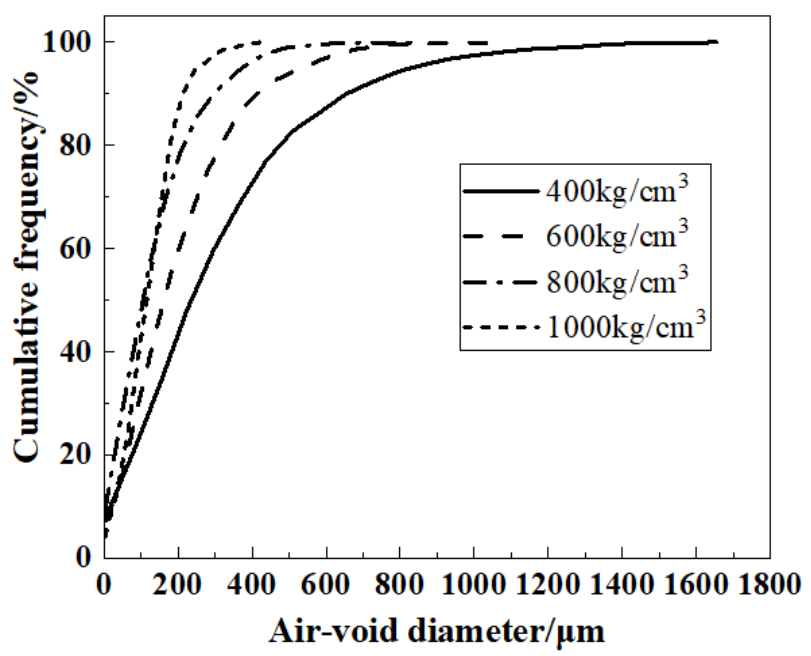

Fig. 8. Pore size distribution of microbial foam concrete with different density grades

\subsection{Characterization of pore structure of microbial foam raw soil material}

\subsubsection{Characterization of unit body}

CT technology can realize non-destructive test. Based on "perspective" imaging of the tested object, 3D spatial images can be obtained through reconstruction, and the hole shape, volume, and connectivity can be determined [29]. The difference between the pore structure parameters of microbial foam concrete with a density grade of 700 and the image analysis method was compared by using characterizing unit body analysis, and the conclusions of pore structure obtained by the image analysis method were verified. Representative elementary physicist Bear to simplify the sample first put volume forward scale of the study of soil seepage [30], which referred to the minimum volume unit that could realize the stability of related properties of rock mass. To obtain the best size of the characterization unit in steady state, a cube model with smaller side length was constructed by taking any point in the 3D space as the center. The porosity was obtained. The side length of the model was increased to keep the center position unchanged, and the porosity values under different side length values were obtained. Fig. 9 is an arbitrarily extracted characterization unit.

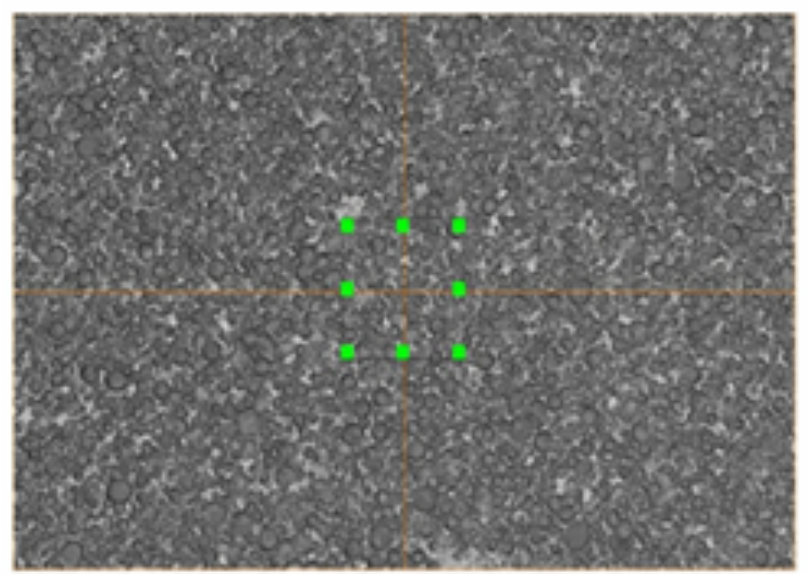

(a) Selected coordinates and range

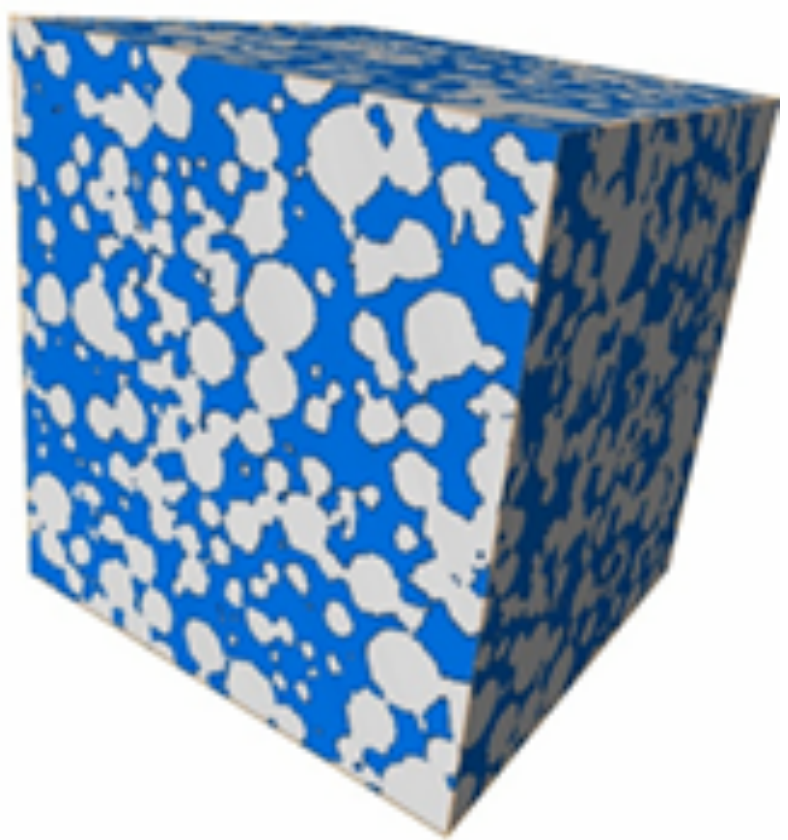

(b) Extracted unit boby

Fig. 9. Extracted characterization unit.

With ROI command and Volume Edit command in Avizo software, cells with different sizes were extracted, and the porosity of the cells was calculated through Materials Statistics command. Fig. 10 shows the influence of unit size on porosity.

Fig. 10 shows the side length of the characterization unit in the range of $0-130$ pixels. The porosity of microbial foam concrete fluctuates greatly with the increase of the characterization size. However, when the side length of the 
characterization unit exceeds 125 pixels, the porosity of microbial foam concrete approaches $52.0 \%$, and the difference from the porosity obtained by image analysis software is $0.4 \%$. Therefore, the side length of the study object should be 200 pixels. Fig. 11 is the gray map and original CT map of the study object. The selected characterization unit is binarized, and its overall phase, pore structure, and solid skeleton are shown in Fig. 12. Most pores in microbial foam concrete are closed pores, and the number of connected pores is relatively small, which is consistent with the conclusion obtained by image analysis method.

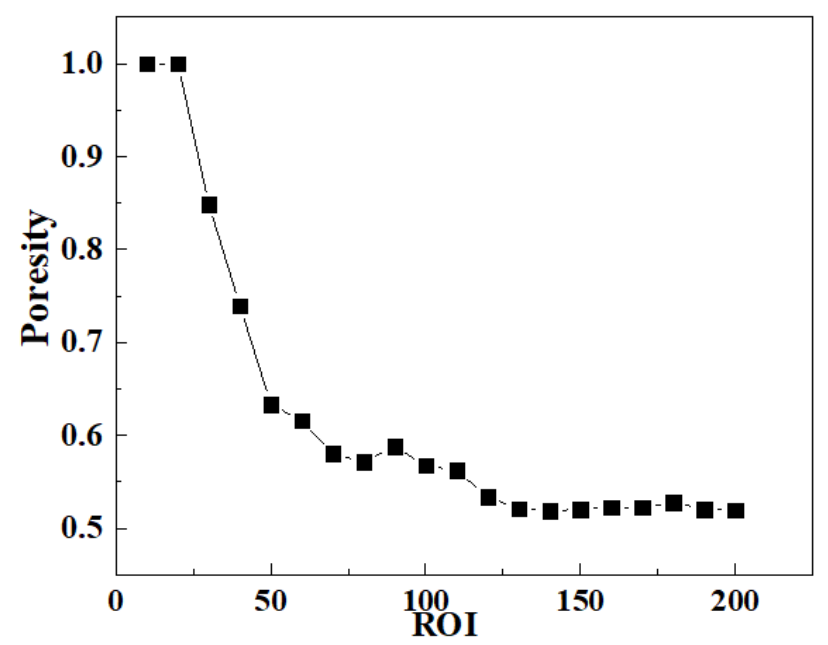

Fig. 10. Influence of the size of characterization unit on porosity
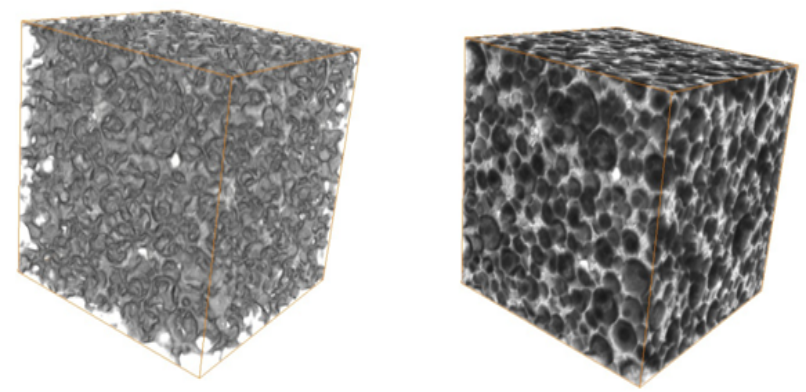

Fig. 11. Original CT image and grayscale image

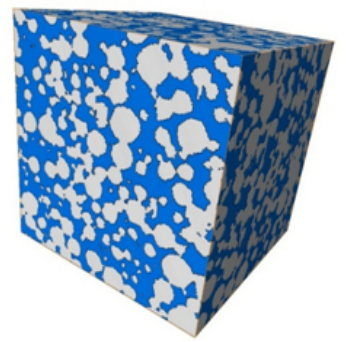

(a) Integral phase

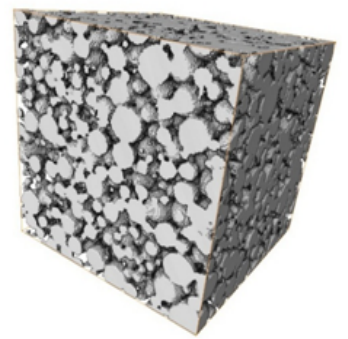

(b) Pore structure

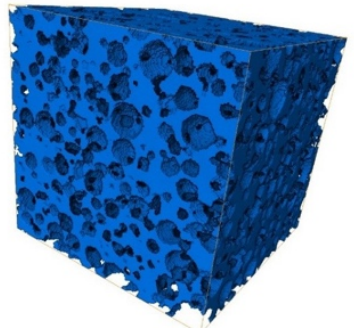

(c) Solid skeleton

Fig. 12. Phase segmentation of characterization unit.
4.3.2 Three-dimensional quantitative characterization of pore structure of microbial foam concrete

Average pore size, pore size distribution, and pore shape factor of the unit were calculated by using Volume Fraction, Auto Skeleton, and Label Analysis commands in Avizo software. The results showed 2100 pores in the study object. Avizo software was used to determine the number of pores. The specific steps are shown in Fig. 13. Fig. 13(a) presents the original CT image, which is rendered to obtain Fig. 13(b). The rendered image is segmented to obtain Fig. 13(c). The principle of the multiphase segmentation command for $2 \mathrm{D}$ CT scan image in Avizo software is watershed algorithm based on morphology. Fig. 13(d) is a pore rendering plan view, and Fig. 14 is a 3D image.

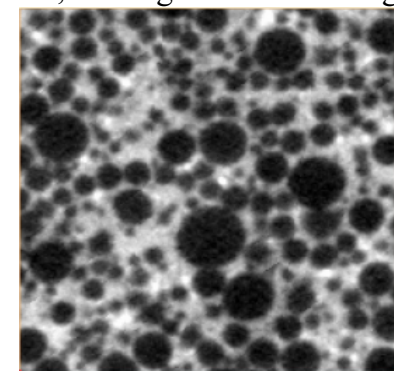

(a) Original CT image

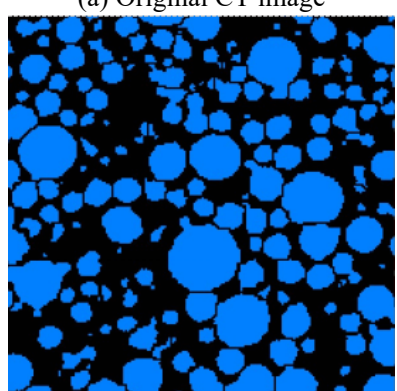

(c) Segmentation processing

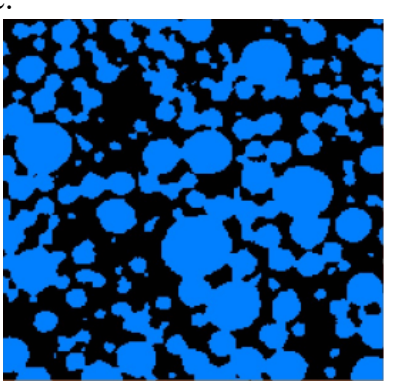

(b) Noise reduction rendering

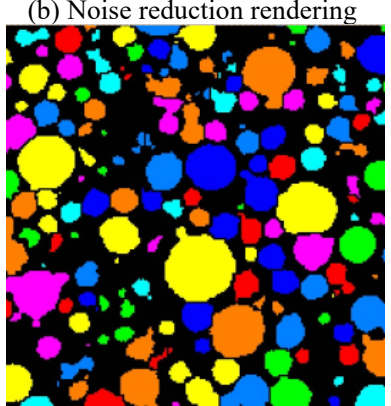

(d) Pore rendering
Fig. 13. Steps to obtain the number of pores.

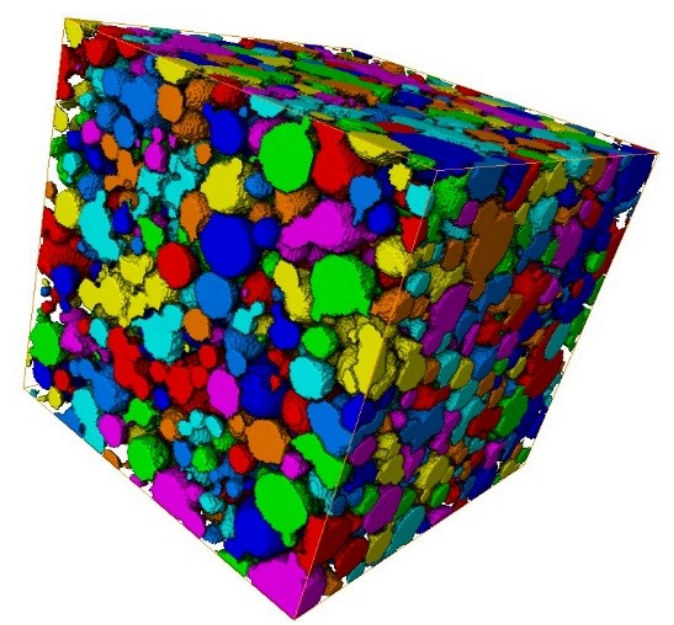

Fig. 14. 3D image of pore structure rendering

Fig. 14 shows that the pore distribution is evenly distributed. When the shape of the pore is close to a sphere, the pore of shape factor approach 1 , and the $3 \mathrm{D}$ image is consistent with the data. The pore size distribution in the 3D reconstruction model of the characterized unit body is $18.48-702.16 \mu \mathrm{m}$, the average equivalent diameter is 123.86 $\mu \mathrm{m}$, the minimum shape coefficient of Sample 1 is 0.231 , the maximum shape coefficient is 0.997 , and the average shape coefficient is 0.903 . The pore size of distribution curve of the characterized unit body is shown in Fig. 15. The 
pore size distribution approximately follows Gaussian distribution.

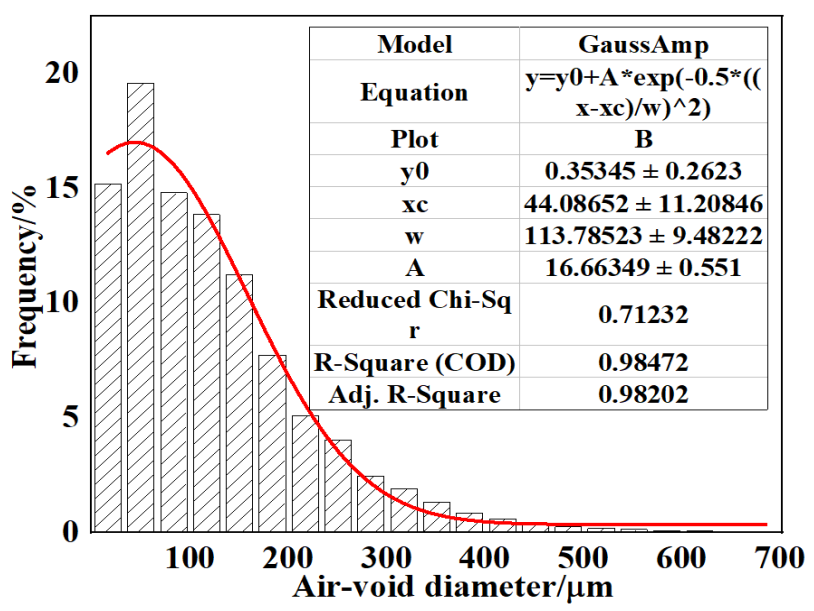

Fig. 15. 3D image pore distribution curve

\section{Conclusions}

To explore the characteristics of foam concrete, the influences of pore structure, porosity, pore size distribution, and pore shape factor on its compressive strength, thermal conductivity, and water absorption rate were revealed in this study. The images of the pores on the surface of microbial foam concrete were collected by using an ultra-depth-offield microscope, and the pore structure was characterized by image analysis software ImageJ. Moreover, the influences of pore structure on the compressive strength, thermal conductivity, and water absorption rate of microbial foam concrete were investigated by means of experimental study and software analysis. Finally, the following conclusions could be drawn:

(1) With the increase of the density grade of microbial foam concrete, the compressive strength and thermal conductivity gradually increased, whereas the water absorption rate, porosity, and average pore diameter decreased. Moreover, the pore shape factor increased, and the value approached 1 . When the density grade of the microbial foam concrete increased from 300 to 700 , the porosity decreased from $74.6 \%$ to $52.4 \%$, and the average pore diameter decreased by $55.6 \%$ from $420.5 \mu \mathrm{m}$ to 186.7 $\mu \mathrm{m}$. The pore shape factor increased to 0.893 , and it was closer to a sphere.

(2) X-CT technology was used to carry out nondestructive scanning and $3 \mathrm{D}$ reconstruction on the pore structure of microbial foam concrete with density grade of 700. The macroscopic pore structure of microbial foam concrete was non-destructively and was quantitatively characterized, which was consistent with the analysis of the reasons for the influence of pore structure on its performance.

(3) The 3D pore structure of the microbial foam raw soil material was analyzed and characterized by using Avizo software, and the characterization unit of $200 \times 200 \times 200$ pixels was selected as the study object. The results showed 2100 pores in the $3 \mathrm{D}$ reconstruction model, with a porosity of $52.0 \%$, minimum pore diameter of $18.48 \mu \mathrm{m}$, maximum equivalent diameter of $702.16 \mu \mathrm{m}$, and average equivalent diameter of $123.86 \mu \mathrm{m}$. The minimum and maximum pore shape factors were 0.231 and 0.997 , respectively, and the average pore of shape factor was 0.903 .

Based on the combination of experiment and theoretical study, a new understanding of foam concrete pore structure was proposed in this study. The non-destructive and quantitative characterization of the macro pore structure of microbial foam concrete was close to the engineering practice, which can provide reference for the study and popularization of foam concrete. This paper focused on the physical and mechanical properties of pore structure, but the durability of biobased foam concrete with different density grades was not considered. Therefore, to realize extensive use in practical engineering, the durability of foam concrete with different density grades must be studied further.

\section{Acknowledgements}

This work was supported by National Key R\&D Program of China 2018YFD1101002.

This is an Open Access article distributed under the terms of the Creative Commons Attribution License.

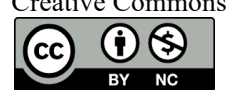

\section{References}

1. H Xiao, R. Tang, X. Wang, "Analysis on the new concrete preparation and its characteristics". Shanxi Architecture, 45(8), 2019, pp. 95-96.

2. Zhang, Z., Provis, J. L., Reid, A., Hao, W., "Geopolymer foam concrete: an emerging material for sustainable construction". Construction and Building Materials, 56(APR.), 2014, pp.113-127.

3. Amran, Y., Farzadnia, N., Ali, A., "Properties and applications of foamed concrete: a review". Construction and Building Materials, 2015, 101(DEC.30PT.1), pp. 990-1005.

4. Harith, I. K., "Study on polyurethane foamed concrete for use in structural applications". Case Studies in Construction Materials, 8, 2018, pp.79-86.

5. Wang, Q., Ren, D., Yuan, H., Sun, P., “Application of Elastic Wave Tomography Technology to Detect Inner Defects in Abutment Concrete". Railway Engineering, 57(10), 2017, pp.37-39.

6. Hao, Y., Ying, T., "Application of elastic wave CT technology in bridge detection". Shanxi Architecture, 43(8), 2017, pp.155-157.

7. Raj, A., Sathyan, D., Mini, K. M., "Physical and functional characteristics of foamconcrete: A review". Construction and Building Materials, 221, 2019, pp.787-799.
8. Dong, H., Zhang, H., Zuo, Y., Gao, P., Ye, G., "Relationship between the size of the samples and the interpretation of the mercury intrusion results of an artificial sandstone". Materials ,11(2), 2018, pp. 201-218.

9. Yang Qing, "Performance and structural regulation of ultra-light foam concrete". Master thesis of Jinan University, China, 2020.

10. Tian, Y., Wu, J., "A comprehensive analysis of the BET area for nanoporous materials”. AIChE Journal. 64(1) ,2017, pp.286-293.

11. Liu, M., Alengaram, U. J., Santhanam, M., Jumaat, M. Z., Mo, K. H., "Microstructural investigations of palm oil fuel ash and fly ash based binders in lightweight aggregate foamed geopolymer concrete". Construction and Building Materials, 120(Sep.1), 2016, pp.112-122.

12. L.Liu, S.Miramini, A.Hajimohammadi, "Characterising fundamental properties of foam concrete with a non-destructive technique". Nondestructive Testing and Evaluation. 34(1), 2019, pp.54-69.

13. Yoshitake, I., Maeda, T., Hieda, M., "Image analysis for the detection and quantification of concrete bugholes in a tunnel lining". Case Studies in Construction Materials, 8, 2018, pp.116130 . 
14. Khan, Z. A., Tranter, T., Agnaou, M., Elkamel, A., Gostick, J., "Dual network extraction algorithm to investigate multiple transport processes in porous materials: Image-based modeling of pore and grain scale processes". Computers and Chemical Engineering, 123, 2019, pp.64-77.

15. Vanderesse, N., Ky, I., Gonzalez, F. Q., Nuno, N., Bocher, P., "Image analysis characterization of periodic porous materials produced by additive manufacturing”. Materials \& Design, 92, 2016, pp.767-778.

16. Tang, H. P., Zhu, J. L., Zhengping, X. I., Xiaobo, D. I, Wang, J., "Impact factors of fractal analysis of porous structure". Science China Technological Sciences, 53(2), 2010, pp.348-351.

17. Lan, M. Z., Dai, D. D., Chen, Z. F., Zhou, J., Liu, C. J., "Relationship between pore structure and properties of ultra light foam cement insulation board". Bulletin of the Chinese Ceramic Society, 35 (2), 2016, pp.518-524.

18. Jun, J., Li J., Niu, Y, H., "Effects of mineral admixtures on the pore structure and properties of ultra light foamed concrete". China Concrete and Cement Products, 278(6), 2019, pp. 63-67.

19. Zhou, L. R., Geng, F., Xi, Y. T., Lin, H., Zhu, Y. X., Xie, J., "Effect of pore structure on water absorption and compressive strength of foam concrete". New Building Materials, 44 (7), 2017, pp. 71-75.

20. Gomes,L., Bellon,O. R. P., Silva, L., "3D reconstruction methods for digital preservation of cultural heritage: A survey", Pattern Recognition Letters, 50, 2014, pp. 3-14.

21. Song, L., Li, X., Yang, Y. G., Zhu, X., Guo, Q., Liu, H., "Structured-light based 3D reconstruction system for cultural relic packaging”, Sensors, 18(9), 2018, doi.org/10.3390/s18092981.
22. Pang, C, M., Wang, S, H., "Characterization of pore structure of foamed concrete and its effect on properties". Journal of Building Materials, 20 (01), 2017, pp.93-98.

23. You, T., Al-Rub, R., Darabi, M. K., Masad, E. A., Little, D., "Net al. Three-dimensional microstructural modeling of asphalt concrete using a unified viscoelastic-viscoplastic-viscodamage model". Construction and Building Materials, 2012, 28(1):531-548.

24. Liu, B. M., "Three-dimensional characterization and permeability of coal based porous carbon". Master thesis of mining and technology University, China, 2019.

25. Zhang, X., Wang, W. X., Yang, D.Y., Zhang, L. L., "Research progress in pore structure characteristics and influencing factors of foamed concrete". China Concrete and Cement Products, 7, 2018, pp.63-68.

26. Hilal, A. A., Thom, N. H., Dawson, A.R., "On entrained pore size distribution of foamed concrete". Construction of Building Materials, 75, 2015, pp.227-233.

27. Lan, M. Z., Dai, D. D., Chen, Z. F., Zhou, J., Liu, C. J., "Study on the relationship between pore structure and properties of ultralight foam cement insulation board". Bulletin of the Chinese Ceramic Society, 35 (2), 2016, pp.5-11.

28. Xi, Y. T., "Study on pore structure and properties of foamed concrete". Master thesis of Nanjing University, China, 2016.

29. Wang, Y. C., Yang, W. G., Li, Z. Y., Liu, W., Liu, B., "Research progress on microstructure detection of cement-based materials by XCT technology". Materials Reports, 33(17), 2019, 2902-2909.

30. Bird, M. B., Butler, S. L., Hawkes, C. D., Kotzer, T., "Numerical modeling of fluid and electrical currents through geometries based on synchrotron X-ray tomographic images of reservoir rocks using Avizo and COMSOL". Computers and Geosciences,73, 2014, pp.616. 